\title{
HORÁRIO ELEITORAL E PARTICIPAÇÃO POLÍTICA NO ESPAÇO MICROPÚBLICO'
}

\author{
Erinaldo Ferreira do Carmo ${ }^{2}$
}

Resumo: Este trabalho descreve e analisa a transformação ocorrida no espaço público e o surgimento do espaço micropúblico como consequência da intensa urbanização, da universalização do acesso à informação e da ampliação da participação política; também investiga a importância do Horário Eleitoral no processo político como instrumento de incentivo à participação política e de mobilização do eleitor comum ao envolvimento no debate situado no espaço micropúblico. Esta obra acompanha a utilização da propaganda eleitoral gratuita na televisão na formação do debate político e na cristalização da intenção de voto do eleitor.

Palavras-Chave: comportamento eleitoral; espaço micropúblico; participação política.

Resumen: Este trabajo describe y analiza la transformación ocurrida en el espacio público y el surgimiento del espacio micropúblico como consecuencia de la intensa urbanización, de la universalidad del acceso a la información y de la amplitud de la participación política; analiza la importancia del horario electoral en el proceso político como incentivo a la participación y movilización del elector común al debate ubicado en el espacio micropúblico. Este trabajo acompaña a la propaganda electoral gratuita en la televisión en textura del debate político y en la cristalización del deseo del ciudadano.

Palabras-clave: comportamiento electoral, espacio micropúblico, participación política.

Abstract: This work describes and analyzes the transformation that took place in public space and the rise of the micropublic space as a result of intense urbanization, universal access to information and the enlargement of the political participation. It investigates the importance of Election Time in the political process as a tool to encourage political participation and mobilization of the common voter involvement in the debate of the situated micropublic space. This job follows the use of free electoral propaganda on television in the formation of the political debate and in the crystallization of the intention of the voter's choice.

Key-words: voting behavior; micropublic space; political participation.

\footnotetext{
${ }^{1}$ Artigo enviado para Revista Eletrônica de Ciência Política em abril de 2010, aceito para publicação em maio do mesmo ano.

${ }^{2}$ Doutorando em Ciência Política pela UFPE e Diretor Acadêmico da Faculdade Metropolitana da Grande Recife.
} 


\section{APRESENTAÇÃO}

Diante da constatação de que o interesse em política e a participação eleitoral têm aumentado progressivamente no país, contrastando com a ideia de expansão da alienação eleitoral, adotamos como uma das principais preocupações deste trabalho a investigação do interesse do eleitor comum pela política e a importância atribuída por ele ao Horário Eleitoral como meio difusor deste interesse.

Para alguns pesquisadores brasileiros (ALDÉ, 2001; LOURENÇO, 2007; LIMA, 2007; CARMO, 2010) os eleitores são atores políticos que agem racionalmente, perseguem seus objetivos e são conscientes de sua importância no processo eleitoral. Estes atores políticos não se vêem como vítimas, mas como agentes integrantes do processo.

É certo que, como agentes ativos, suas opiniões, atitudes e objetivos estão condicionados, não só pelos instrumentos que dispõem e pelas situações estruturais e institucionais, mas também pela limitação de sua capacidade subjetiva e cognitiva. No entanto, estes condicionamentos e limitações são superados pelo envolvimento com os grupos, aos quais estes agentes estão atrelados, e pela utilização das informações.

\section{METODOLOGIA}

Através de survey realizado nas Eleições Gerais de 2002 e 2006 procuramos identificar a audiência do Horário Eleitoral e sua utilização pelos eleitores recifenses para escolher seus candidatos. Em outro survey, realizado na campanha de 2008, procuramos comparar o eleitor recifense com os de outros municípios vizinhos que têm acesso diferenciado a esta programação, além de mensurar algumas variáveis de identificação da influência da propaganda eleitoral nas discussões dos grupos.

Os dois primeiros surveys foram realizado entre os dias 30 de setembro e 4 de outubro de 2002 e 25 e 29 de setembro de 2006, em todas as zonas eleitorais do Recife. O terceiro survey foi realizado entre os dias 29 de setembro e 3 de outubro de 2008, nos municípios de Jaboatão dos Guararapes, Olinda e Recife. Em cada edição foram aplicados 408 questionários, em abordagem de fluxo, para uma amostra estratificada proporcionalmente. Para todas as pesquisas, a margem de erro utilizada foi de cinco pontos percentuais, para mais ou para menos, com um nível de confiança de 95\%.

Incluímos neste trabalho dados qualitativos extraídos de entrevistas em seções de grupos focais. Os encontros foram realizados semanalmente com eleitores indecisos, classificados em quatro categorias, cada uma composta por cinco pessoas, de acordo com o interesse em política e o acesso à informação política. 
Assim foram formados os grupos:

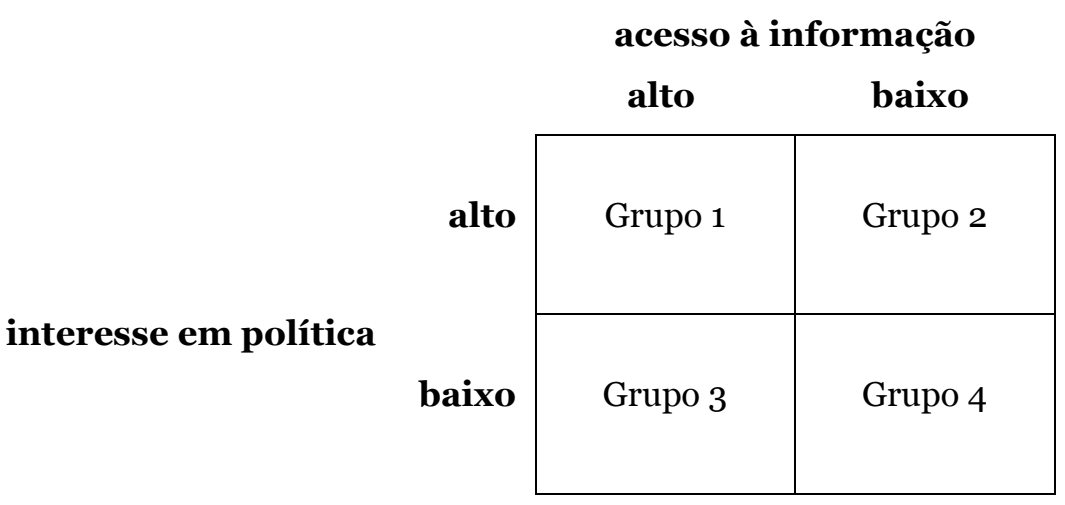

\section{ACOMPANHAMENTO DO ELEITORADO}

Entre os eleitores abordados pela pesquisa quantitativa, $15,2 \%$ se consideraram bastante interessados em política e 56,2\% afirmaram ter um interesse regular, enquanto $28,4 \%$ se declararam pouco interessados. As tabelas 1 e 2 mostram o interesse em política a partir da faixa de idade e da escolaridade do eleitor. Esta identificação do interesse do eleitor pela política, presente nos diferentes estratos sociais, verificada através das variáveis empregadas no survey, contraria a imagem popularmente construída de um eleitor desinteressado.

Tabela 1 - Interesse em política por faixa etária (Recife - 2006)

\begin{tabular}{l|r|r|r} 
& \multicolumn{3}{c}{ Interesse em política (\%) } \\
\hline Faixa etária & Bastante & Regular & \multicolumn{1}{c}{ Pouco } \\
\hline 16 a 24 anos & 13,3 & 57,3 & 29,3 \\
\hline 25 a 34 anos & 17,7 & 58,3 & 24,0 \\
\hline 35 a 44 anos & 16,3 & 44,2 & 39,5 \\
\hline 45 a 59 anos & 15,4 & 58,2 & 26,4 \\
\hline 60 anos ou mais & 11,6 & 66,7 & 21,7 \\
\hline
\end{tabular}

Fonte: Erinaldo F. do Carmo

Tabela 2 - Interesse em política por escolaridade (Recife - 2006)

\begin{tabular}{l|r|r|r} 
& \multicolumn{3}{c}{ Interesse em política (\%) } \\
\cline { 1 - 4 } Escolaridade & Bastante & Regular & \multicolumn{1}{c}{ Pouco } \\
\hline Analf./semianalf. & 1,2 & 56,0 & 41,8 \\
\hline Ens. Fundam. I & 19,1 & 46,4 & 31,5 \\
\hline Ens. Fundam. II & 17,3 & 54,5 & 28,2 \\
\hline Ensino Médio & 16,7 & 59,1 & 24,2 \\
\hline Ensino Superior & 8,2 & 65,3 & 26,5 \\
\hline
\end{tabular}

Fonte: Erinaldo F. do Carmo

Nesta linha, Luciana Veiga (2001), numa análise psicológica da relação do eleitor com a propaganda política, descreve o eleitor brasileiro como um sujeito cognitivo ativo, centrado nos grupos de referência e em seu ambiente social, dotado do 
que ela chama de "ideologia do cidadão comum”. Seu entendimento é de um eleitor participativo, o qual, mesmo condenando algumas práticas políticas e seus autores, se envolve com o processo na busca de conquistas, tanto pessoais quanto coletivas.

Contudo, Veiga reconhece que há uma falta de recursos cognitivos no eleitor comum. Este não conhece o funcionamento da política, pouco sabe do processo eleitoral, sua estrutura e importância, mas há, ainda assim, um diálogo entre candidatos e eleitores. Esta falta de recursos cognitivos é suprida pelo diálogo, sendo de suma importância a propaganda eleitoral gratuita, a qual permite ao eleitor conhecer e agir ativamente na política. Neste caso, o Horário Eleitoral tem um papel primordial, tornando-se instrumento de aproximação entre o candidato e o eleitor, um meio de redução da alienação. O Horário Eleitoral mobiliza a população eleitoral e atende à demanda de informação "na medida em que aumenta a exposição dos políticos e disponibiliza para o eleitor um discurso assimilável” (VEIGA, 2002, p. 188).

Lourenço (2007, p. 124) identifica que o eleitor possui opiniões, atitudes e juízo de valores sobre a esfera política, os quais não são gratuitos nem aleatórios. $O$ eleitor comum age de forma racional, e seu conhecimento sobre política é criado a partir de suas experiências pessoais e do seu envolvimento com seus grupos.

A simplicidade do eleitor comum não o afasta do processo eleitoral, nem o impede de buscar informações que complementem suas limitações cognitivas. Almeida (2007), numa tentativa de interpretar como o brasileiro pensa a política, avalia que a questão educacional diferencia as formas de pensamento e interpretação da realidade. Para ele, a diferenciação no nível educacional é responsável pela falta de uniformidade social no país. Mas o que constatamos nos grupos focais foi que a diferença no nível educacional altera a percepção do funcionamento da política e de suas competências, mas não modifica a interpretação dos valores cobrados de todos os que ocupam cargos eletivos, nem altera a concepção do que é correto ou não na vida pública e na administração da coisa pública.

Mesmo os cidadãos menos escolarizados e pouco interessados em questões políticas conhecem suas responsabilidades, enquanto eleitor, e as responsabilidades dos ocupantes de cargos políticos. A totalidade dos eleitores abordados nesta pesquisa não se mostrou dispersa por completo do processo eleitoral. Mesmo os que não se enxergam na política reconhecem que em algum momento tomam partido e se envolvem. Não fazem uso cotidiano da política, mas no período eleitoral assumem a responsabilidade de escolher o que lhes parece melhor. Quando começam as disputas pelos cargos eletivos, a aparente inércia é quebrada, e a mobilização em torno dos nomes e dos cargos ganha as ruas. 
Segundo Aldé (2001, p. 188), as informações procuradas pelo eleitor, presentes em diversos canais, são plenamente encontradas, e de forma mais assimilável, no Horário Eleitoral. Primeiramente, a propaganda eleitoral gratuita atende a esta necessidade de informação assimilável pelo eleitor comum. Em seguida, as informações são processadas com os conhecimentos prévios que o eleitor possui. Finalmente, essas informações são validadas ou refutadas nos diálogos com os amigos.

O interesse pela política é aguçado com o Horário Eleitoral, o qual serve aos eleitores para identificar os candidatos e conferir sua apresentação em acordo com sua vida política pregressa. Serve para comparação das posturas, análise das acusações, bem como avaliação das defesas e justificativas apresentadas pelos candidatos. $\mathrm{O}$ debate realizado no programa televisivo é conferido nos diálogos posteriores nos grupos de convívio. Nestes diálogos, o que foi veiculado no Horário Eleitoral ganha destaque. Isto porque as imagens que aparecem na televisão possuem um elevado poder de despertar lembranças acerca dos fatos noticiados, o que permite a comparação com ações passadas, e confere ao meio um poder de prova, evidências factuais. Como na televisão a veracidade narrada é reforçada pela irrefutabilidade do que se vê com os próprios olhos (ALDÉ, 2001, p. 172), o acompanhamento do Horário Eleitoral também é feito pelo eleitor para confirmar ou refutar o que é repercutido nos grupos de convívio.

Com essa descrição da participação do eleitorado, entendemos que a busca pela informação e o desejo de conhecer melhor, e acertar, na escolha, afastam do eleitor comum o sentido de alienação. O eleitor possui uma opinião (VEIGA, 2001), que é formada por ele próprio (ALDÉ, 2001) a partir dos meios que dispõe (LOURENÇO, 2007).

\section{O USO DO HORÁRIO ELEITORAL}

Pesquisa realizada em 2006 para compor este trabalho revelou que o horário destinado à propaganda eleitoral gratuita possui boa audiência junto ao eleitorado recifense. O Horário Eleitoral, transmitido pela televisão, é acompanhado diariamente por $17,7 \%$ dos eleitores; $20 \%$ assistem de quatro a cinco dias por semana; 20,5\% assistem de dois a três dias; 21\% assistem apenas um dia semanalmente; e 20,6\% não assistem. Para a grande maioria dos pesquisados, 65,8\%, o Horário Eleitoral ajuda na escolha do candidato.

O eleitor busca no contato virtual com o candidato uma identificação maior do postulante ao cargo público eletivo. Quanto mais importante for o cargo, na compreensão do eleitor, maiores serão as exigências aos postulantes. A análise da 
imagem, e a associação desta ao cargo, também foi constatada nesta pesquisa com os grupos focais. Por exemplo, as imagens da candidata Heloisa Helena, apresentadas no Horário Eleitoral, e analisadas pelos eleitores pesquisados, foram identificadas, em todos os grupos trabalhados, independente do acesso à informação e do interesse por política, como incompatíveis às exigências da função presidencial, e suas atitudes impróprias a um chefe de Estado. Em resumo, ela foi identificada pelos pesquisados como alguém que não se portava à altura do cargo.

A rejeição à postura da candidata provocou a rejeição também aos seus discursos. O excesso de denúncias feitas pela presidenciável contra outros candidatos não teve aceitação e não lhe deu credibilidade. Em pesquisa semelhante, Veiga (2002, p. 193) observa, em sua avaliação qualitativa sobre a razão do voto, que há no eleitor comum um bloqueio às mensagens dos candidatos com os quais ele não se identifica. Veiga confirma, ainda, que a propaganda adversária só gera alguma tensão se contiver argumentos sérios, não as simples denúncias. Não é a quantidade de denúncias e sim a sua seriedade que pode causar algum impacto. Em seu trabalho foi possível perceber, também, que os eleitores que já possuíam uma posição sobre o seu voto tendiam a prestar mais atenção na propaganda dos seus candidatos. Desta forma, seus valores e atitudes serviram de bloqueio para o diálogo com os outros candidatos, dificultando a comunicação.

Notamos que as denúncias envolvendo candidatos passam pela avaliação do eleitor, que julga o fato consultando seus conhecimentos anteriores sobre o caso e as opiniões dos seus pares em seu grupo de convívio. Por isto, ainda que expostos às mesmas informações, os eleitores selecionam e processam essas informações de forma diferenciada, chegando a resultados também diferenciados, e até mesmo divergentes.

Quando o eleitor compreende o jogo político, e as intenções que permeiam as denúncias, passa a considerar o que está sendo dito, e por quem está sendo dito. Assim, filtra os conteúdos das mensagens.

Para Albuquerque e Dias (2002, p. 15), o fato de o Horário Eleitoral ser exibido em blocos sequenciados acirra a competição, permitindo a comparação direta entre os concorrentes. Mas, por outro lado, como efeito colateral, agrava o problema do excesso de informações em pouco tempo. A grande quantidade de denúncias em um mesmo programa pode, num primeiro momento, não permitir ao eleitor a melhor escolha, mas fazê-lo repudiar todo o processo. Pode, ainda, não deixá-lo escolher bem, por não haver tempo hábil para processar e investigar todas as acusações publicadas.

A exposição de diferentes candidatos em um mesmo espaço e a possibilidade de denúncias e defesas criam as condições propícias para um julgamento público midiatizado, deixando o eleitor comparar diretamente cada um dos concorrentes 
apresentados. Dentro do seu efeito colateral, a utilização excessiva da televisão pela política para acusações e defesas pode incentivar a aceitação da mídia como fórum legítimo de julgamento político, acima dos espaços legais.

O progressivo aumento na oferta da informação pela televisão, impondo-se como meio predominante de comunicação que cobre todas as áreas da vida social, incluindo a política, funde a mídia com o próprio cenário e o virtual com o real. Segundo Matos (1994, p. 17), "tanto no nível do intercâmbio político como no simbólico, o funcionamento do sistema político nas democracias das sociedades modernas está sendo cada vez mais determinado pela mídia." Os eventos eleitorais passam a usar, e a depender, cada vez mais deste recurso para o seu desempenho eficaz. Com isto, “o candidato é julgado mais pela sua competência comunicativa do que política”.

A busca por mais informações aumenta conforme a campanha se aproxima do final. É assim com o Horário Eleitoral, que passa a ser consultado como um valioso canal de informação. Sua audiência cresce da primeira para a última semana, e as conversas sobre temas políticos por ele apresentados aumentam no mesmo ritmo. Apenas oito, dos 20 entrevistados, debateram sobre a eleição no transcorrer da primeira semana do Horário Eleitoral. Na última semana, todos tinham, em algum momento, conversado com alguém sobre política (na rua, no local de trabalho ou em casa).

Esta ampliação da audiência e do debate mostra o efeito multiplicador do Horário Eleitoral. Mesmo o eleitor que comumente não assiste aos programas toma conhecimento dos seus pontos mais relevantes, os quais são expostos e comentados por outras pessoas em múltiplos espaços. A ampla exposição dos temas políticos, por sua vez, faz com que os membros dos grupos busquem mais informações no Horário Eleitoral, no mínimo para confirmar as informações recebidas e para se inteirar dos assuntos, participando ativamente dos debates.

$\mathrm{Na}$ pesquisa comparativa realizada em 2008 para ampliar este trabalho, percebemos que, nos três municípios conurbados da Grande Recife, o debate político se amplia na medida em que há maior divulgação do Horário Eleitoral. No Recife a programação eleitoral é transmitida por cinco canais abertos de televisão; em Olinda a transmissão é oferecida por apenas um canal aberto; e em Jaboatão dos Guararapes não há emissora local que transmita as campanhas dos candidatos do município. A transmissão é ampla em Recife, reduzida em Olinda e ausente em Jaboatão. Isto se reflete no debate entre os eleitores de cada município. 
Tabela 3 - Uso do Horário Eleitoral

\begin{tabular}{l|c|c|c}
\hline Situação dos eleitores & Recife & Olinda & Jaboatão \\
\hline $\begin{array}{l}\text { Conhecem os candidatos } \\
\text { majoritários do seu município }\end{array}$ & $38,7 \%$ & $26,5 \%$ & $23,8 \%$ \\
\hline $\begin{array}{l}\text { Identificaram os partidos dos } \\
\text { principais candidatos }\end{array}$ & $13,2 \%$ & $8,8 \%$ & $8,5 \%$ \\
\hline $\begin{array}{l}\text { Assistem ao Horário Eleitoral } \\
\text { mais de uma vez por semana }\end{array}$ & $55,8 \%$ & $48,2 \%$ & $26,6 \%$ \\
\hline $\begin{array}{l}\text { Conversam com outras } \\
\text { pessoas sobre política }\end{array}$ & $63,2 \%$ & $58,6 \%$ & $36,8 \%$ \\
\hline
\end{tabular}

Fonte: Erinaldo F. do Carmo

Nestes três municípios pesquisados, os principais locais onde ocorrem as discussões políticas são: trabalho, escola/faculdade, bar/restaurante/clube/praia, casa/família, vizinhos/rua, igreja, ônibus (nesta ordem). Em Recife, onde há mais canais de televisão transmitindo a propaganda eleitoral, os candidatos são mais conhecidos. Em Jaboatão, onde não há transmissão televisiva do Horário Eleitoral para os seus candidatos, os eleitores têm um conhecimento menor dos concorrentes. Também em Jaboatão, as pessoas conversam menos sobre assuntos políticos.

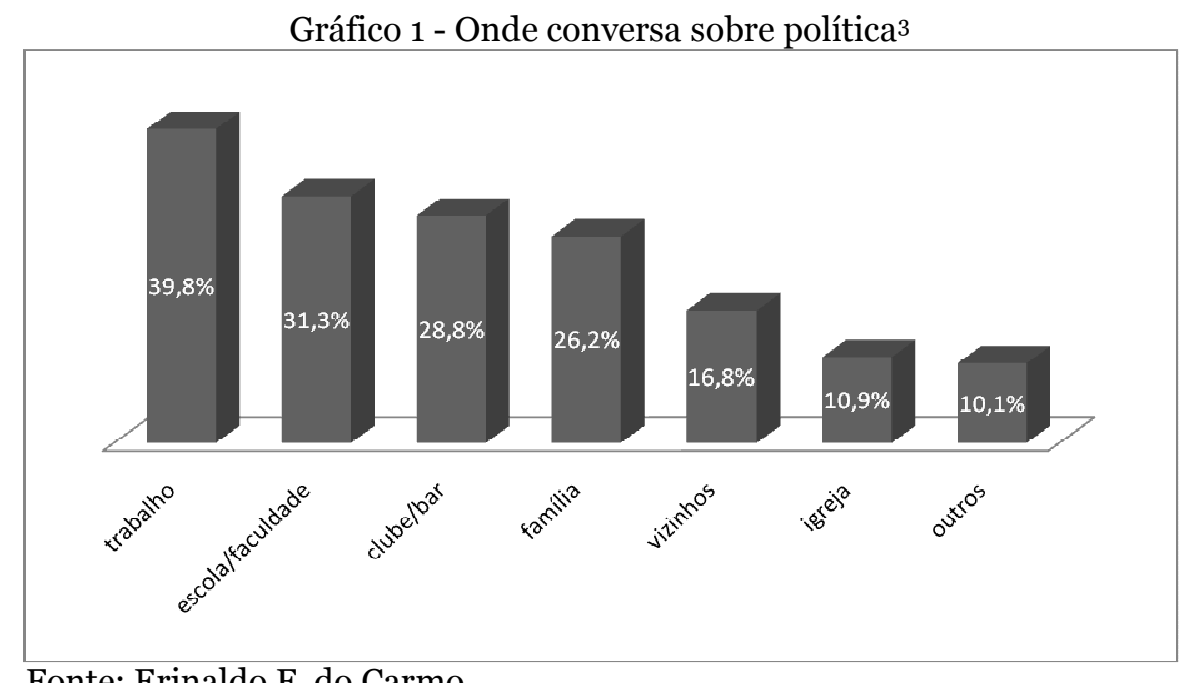

Fonte: Erinaldo F. do Carmo

A televisão, de forma geral, possui essa capacidade de fornecer assuntos para a comunicação interpessoal, e o Horário Eleitoral, especificamente, fornece subsídios ao debate político. Isto ocorre porque a recepção da mensagem televisiva ultrapassa o espaço familiar, no qual o indivíduo é interpelado, e atinge a atividade coletiva, levada por esse indivíduo, agora como membro de grupos secundários.

3 Aos entrevistados era permitido indicar mais de uma fonte, assim a soma ultrapassa os $100 \%$. 


\section{O DEBATE NO ESPAÇO MICROPÚBLICO}

O espaço micropúblico correspondente ao espaço público urbano midiatizado. Compreende a esfera onde os debates políticos ocorrem em pequenos grupos formados por pessoas próximas, consumidoras das informações da mídia, e que se reúnem, ainda que em espaços privados, não necessariamente para conversar sobre política, mas que acabam tomando parte deste tema (CARMO, 2010, p. 11).

Os indivíduos têm a necessidade de se expressar e, enquanto cidadãos, precisam externalizar sua interpretação da realidade e pronunciar suas visões do mundo político. O espaço micropúblico lhes permite este pronunciamento político.

No espaço micropúblico as atitudes políticas manifestam-se numa série de argumentos e discursos produzidos pelos sujeitos para justificar e avalizar as opiniões que expressam. Este espaço para discussão política é perfeitamente retratado por Aldé (2001, p. 116), ao identificar que, embora as atuais democracias representativas não obriguem o eleitor a expressar publicamente suas opiniões e argumentos políticos, estes não se importam em declarar e argumentar em defesa de sua posição. Nos grupos, a vivência da política ocorre, frequentemente, em termos discursivos e os espaços para o debate político são os mais diversos, como as

conversas em família, as discussões e arengas ouvidas nas vans e ônibus, muitas vezes tendo como tema notícias veiculadas pelos meios de comunicação, além das narrativas e exemplos presentes na própria mídia, que dão substância ao cotidiano da política (ALDÉ, 2001, p. 116).

Os indivíduos argumentam sobre suas escolhas e se utilizam de informações da mídia, experiências pessoais e de terceiros, para subsidiar esses argumentos. Isso faz da mídia um instrumento privilegiado de referência, fornecedor de atalhos acessíveis e aceitáveis na elaboração de justificativas para as posições políticas.

Para Veiga (2002, p. 184) as opiniões sobre o pleito eleitoral se cristalizam nos diálogos interpessoais, tendo o Horário Eleitoral o importante papel de fornecer ao eleitor argumentos para defender sua intenção de voto nas conversas do dia a dia.

Os argumentos e contra-argumentos são elaborados a partir de fontes diversas, mas é o Horário Eleitoral que fundamenta e escala os temas do debate. $\mathrm{O}$ eleitor seleciona e processa as mensagens veiculadas pelos partidos e candidatos, a partir do seu estoque de conhecimentos e valores, ${ }^{4}$ depois valida suas informações no

$4 \mathrm{O}$ eleitor não considera apenas ganhos possíveis e pessoais, mas também valores, como moral, honestidade, crença (CERVI, 2002, p. 6). 
espaço político urbano. Desta forma, o Horário Eleitoral se estabelece como peça fundamental de promoção do debate político no espaço micropúblico.

Neste trabalho percebemos que a aceitação do candidato está relacionada à aprovação de sua apresentação (discurso + imagem) no Horário Eleitoral. Entre os eleitores decididos a não mudar o voto, a aprovação da imagem e do discurso é maior que a reprovação. Já entre os eleitores que ainda podiam mudar o voto, para os dois cargos do Executivo, mesmo na última semana de campanha, a aprovação da apresentação do seu candidato na propaganda eleitoral é inferior.

Tabela 4 - Decisão de voto e avaliação do candidato no Horário Eleitoral

\begin{tabular}{l|l|c|c|c|c|c}
\multicolumn{2}{c}{} & \multicolumn{6}{c}{ Avaliação (\%) } \\
\hline Cargo & Posição do eleitor & Ótimo & Bom & Regular & Ruim & Péssimo \\
\hline \multirow{2}{*}{ Governador } & Está decidido & 21,9 & 59,7 & 14,2 & 2,3 & 1,8 \\
\cline { 2 - 8 } & Ainda pode mudar & 12,9 & 33,3 & 37,0 & 12,8 & 3,8 \\
\hline \multirow{2}{*}{ Presidente } & Está decidido & 29,8 & 50,1 & 17,2 & 1,0 & 1,8 \\
\cline { 2 - 8 } & Ainda pode mudar & 6,1 & 46,8 & 42,2 & 2,1 & 2,0 \\
\hline
\end{tabular}

Fonte: Erinaldo F. do Carmo

Como as campanhas eleitorais são centradas nos candidatos majoritários, isto cria uma avaliação diferenciada, por parte do eleitorado, entre os majoritários (presidente, governador, prefeito e senador) e os proporcionais (vereador, deputados estadual e federal). Mesmo entre os majoritários, a concentração da campanha é maior nos candidatos aos cargos do Executivo. Por este motivo, a avaliação da imagem e do discurso dos candidatos ao Executivo é mais comum entre o eleitorado. Nas campanhas dos concorrentes ao Legislativo a situação é inversa: os eleitores sentem dificuldade de compará-los e avaliá-los, sobretudo pela limitação de suas exposições.

Como os partidos e coligações privilegiam os candidatos majoritários, em detrimento dos proporcionais, isto é facilmente identificado pelos eleitores e comumente criticado pelos candidatos ao Legislativo, os quais se tornam meros cabos eleitorais dos candidatos majoritários.

Nas campanhas proporcionais, os eleitores não reconhecem os candidatos que estiveram no ar por 30 ou 15 segundos. Não aprovam os que aparecem em frações tão curtas de tempo, pois não dá para identificar nome, número e partido. São candidatos que aparecem sem a voz própria, enquanto um narrador pronuncia rapidamente seus dados. Geralmente isto ocorre em partidos pequenos, com pouco tempo no Horário Eleitoral e muitos candidatos inscritos.

$\mathrm{Na}$ pesquisa de acompanhamento na distribuição do tempo no Horário Eleitoral e sua comparação com o resultado final da campanha percebemos a importância para os candidatos a cargos legislativos da aparição no Horário Eleitoral. Na disputa para a Câmara dos Deputados, dos 28 candidatos com alta exposição no 
Horário Eleitoral 16 se elegeram, e dos 15 que tiveram uma exposição mediana apenas cinco conseguiram se eleger.

Tabela 5 - Exposição dos candidatos proporcionais no Horário Eleitoral5

\begin{tabular}{l|l|r|r|r|r}
\cline { 3 - 7 } & BAIXA & MÉDIA & ALTA & Total \\
\hline Assembléia & $\mathrm{N}^{0}$ de Candidatos & 489 & 19 & 6 & 514 \\
\cline { 2 - 7 } Legislativa & Deputados Eleitos & 33 & 11 & 5 & $\mathbf{4 9}$ \\
\hline \multicolumn{7}{|c|}{$\begin{array}{l}\text { Câmara dos } \\
\text { Deputados }\end{array}$} & $\mathrm{N}^{0}$ de Candidatos & 186 & 15 & 28 & $\mathbf{2 2 9}$ \\
\cline { 2 - 7 } & Deputados Eleitos & 4 & 5 & 16 & $\mathbf{2 5}$ \\
\hline
\end{tabular}

Fonte: Erinaldo F. do Carmo

A exposição na TV, na propaganda eleitoral, torna o candidato mais conhecido e seus temas mais debatidos, porém, não tem uma relação precisa com a conquista de votos: entre os candidatos à Câmara dos Deputados e à Assembléia Legislativa a classificação no resultado final da eleição não é proporcional ao número de aparições na propaganda eleitoral na televisão ${ }^{6}$.

\section{MOBILIDADE ELEITORAL}

Para compreender como se processa a escolha do eleitor, e a influência do Horário Eleitoral na promoção do debate que molda essa escolha, pesquisamos a mobilidade na intenção de voto do eleitor recifense.

Nas eleições gerais de 2002, 11,8\% dos eleitores haviam mudado de candidato (governador e presidente) ao menos uma vez durante o período oficial de campanha. Nas eleições de 2006, esse percentual foi de 19,5\%. Isso representa um acréscimo no quantitativo de eleitores que alteraram sua intenção de voto conforme o andamento das campanhas.

Em 2002, faltado apenas uma semana para o dia de votação, 15,6\% dos eleitores afirmaram que ainda podiam mudar de candidato à presidência da República e $15,2 \%$ podiam mudar de candidato ao governo do Estado. Nas eleições de 2006, na última semana de campanha, estes quantitativos subiram para 26,4\% e 27,6\%, respectivamente. Esses percentuais não incluem os eleitores indecisos. São eleitores com candidatos definidos, mas que podiam mudar a intenção de voto conforme ocorresse alguma alteração na campanha, como um fato novo divulgado na propaganda eleitoral envolvendo seus candidatos.

\footnotetext{
5 Enquadram-se em baixa exposição os candidatos que apareceram até 15 vezes; em média exposição os que apareceram entre 16 e 30 vezes; e em alta exposição os que apareceram acima de 30 vezes. O máximo que um candidato podia aparecer foi de 45 vezes.

${ }^{6}$ Neste caso há de se considerar, também, que as cadeiras são distribuídas entre os partidos e coligações. Portanto, candidatos bem votados podem não ser eleitos.
} 
Gráfico 2 - Mobilidade eleitoral (\%)

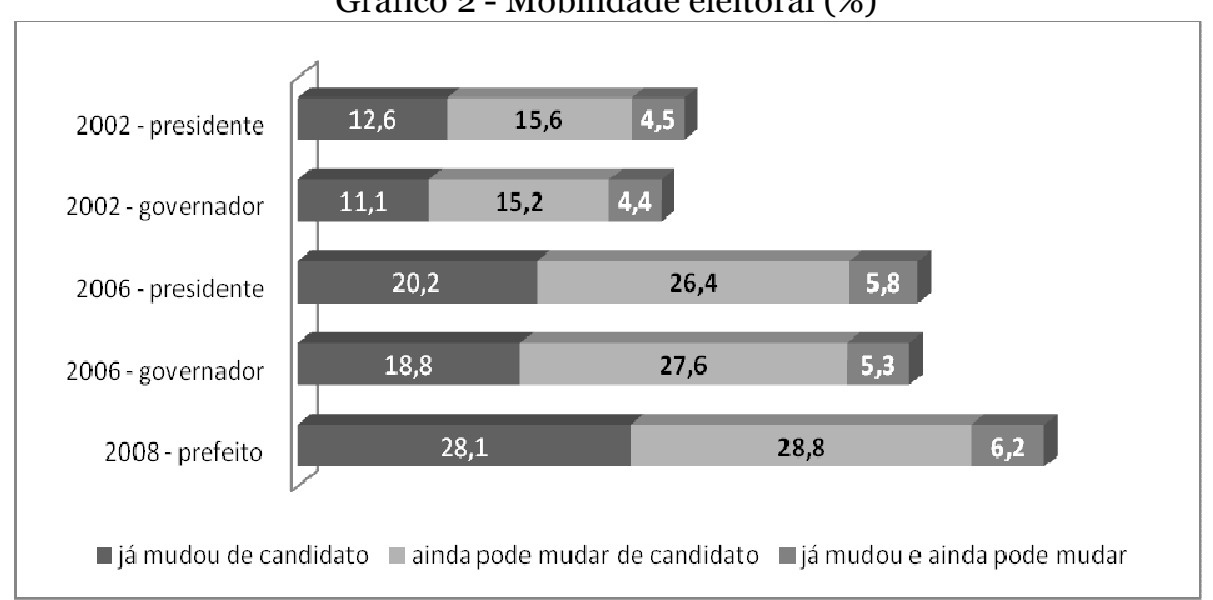

Fonte: Erinaldo F. do Carmo

Este dinamismo não representa uma volatilidade do eleitor, e sim a mobilidade de escolha produzida pela troca de informações e a confrontação dessas informações com os conhecimentos prévios, com os valores pessoais e com a contrainformação dos seus pares em seus grupos de convivência. Representa, também, o convencimento dialógico, característica própria do espaço público que se reproduz agora no espaço micropúblico.

A escolha do eleitor tem um efeito cumulativo. Segundo Matos (1994, p. 16) ele considera o conhecimento anterior sobre o assunto, as novas informações recebidas e os valores pessoais. Assim como o conhecimento, as informações e os valores se alteram, as escolhas também são alteradas durante o processo. Nesta dinâmica, os indivíduos constroem e reconstroem sua própria representação da realidade. Por isto, a mudança de candidato não significa, necessariamente, volatilidade, mas o resultado de um processo de comparação e escolha que envolve diálogos e influências. Também não significa que o eleitor não tenha bases ideológicas, visto que as alterações são mais comuns entre nomes de uma mesma coligação ou corrente política (BRAGA, 2006, p. $61)$.

Assim, o Horário Eleitoral, que num primeiro momento faz o eleitor perceber a real proximidade das eleições e a necessidade de fazer as escolhas (OLIVEIRA, 1999, p. 8; VEIGA, 2002, p. 188; LOURENÇO, 2007, p. 130), serve de fonte de informação política aos indivíduos para atender aos seus interesses pela política e orientar suas preferências e as dos seus pares. Em nossa pesquisa, mais da metade (51,1\%) dos eleitores entrevistados informou que já tentou convencer alguém do seu grupo de convívio a votar no seu candidato. Este percentual é maior entre os que têm bastante interesse em política e, principalmente, entre os que assistem com maior regularidade ao Horário Eleitoral. 


\section{USO DOS MEIOS}

Os estudos aqui realizados revelam que os meios de comunicação mais utilizados pelos eleitores, como fonte de informação política, são a televisão, o rádio, o jornal e a internet, nesta ordem. Os amigos aparecem como uma importante fonte de informação, com percentual inferior apenas à televisão e ao rádio.

A televisão é o meio mais utilizado em todos os estratos pesquisados. Identificamos que quase a totalidade dos que indicaram os amigos como fonte de informação política é também usuária da televisão e de um segundo meio (rádio, jornal ou internet). Isto demonstra que os eleitores que debatem a política em seus grupos de convívio são pessoas que possuem mais informações de fontes diversas, mas principalmente da televisão.

Gráfico 3 - Fontes de informação política por gênero (\%)

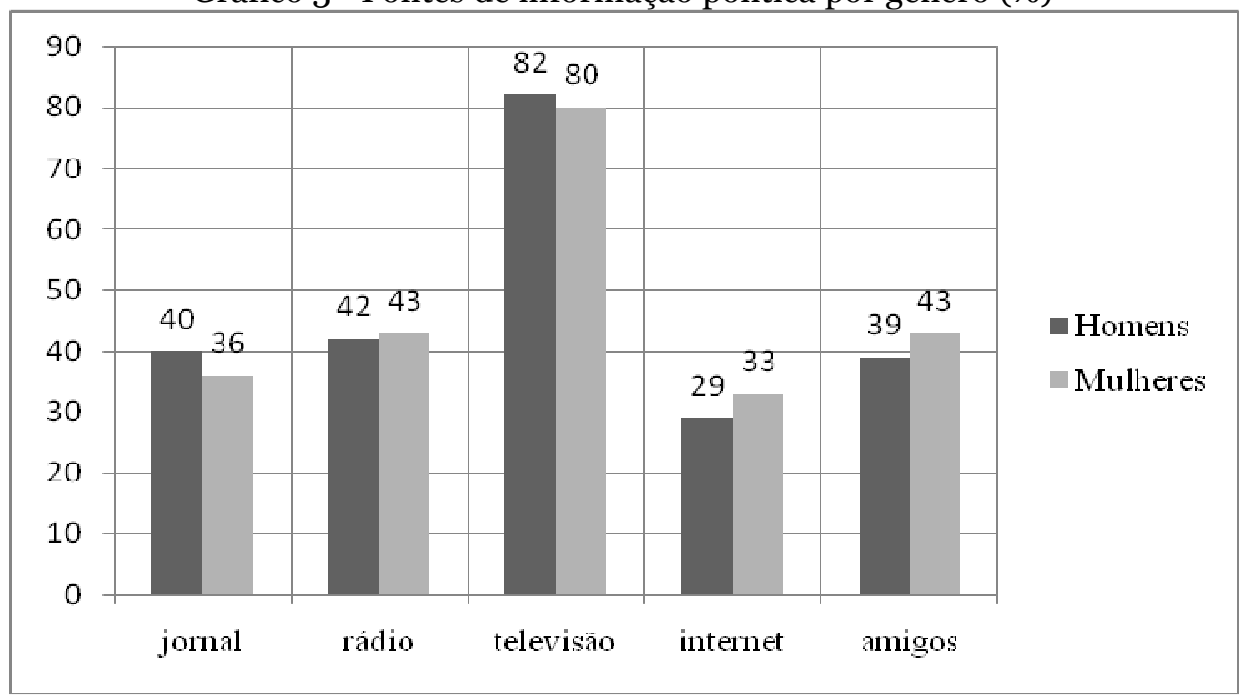

Fonte: Erinaldo F. do Carmo

Em todos os grupos pesquisados a televisão desponta como principal veículo fornecedor de informações política aos eleitores. Entretanto, o que se destaca neste caso é que entre os eleitores com menos escolaridade e entre os eleitores mais velhos o domínio da televisão é absoluto, não só porque apresenta os mais elevados percentuais de utilização, mas principalmente por estar numa vantagem muito além dos outros veículos. A televisão é excessivamente utilizada enquanto as demais fontes de informação apresentam uma utilização bastante reduzida, principalmente o jornal e a internet. 
Gráfico 4 - Fontes de informação e interesse em política

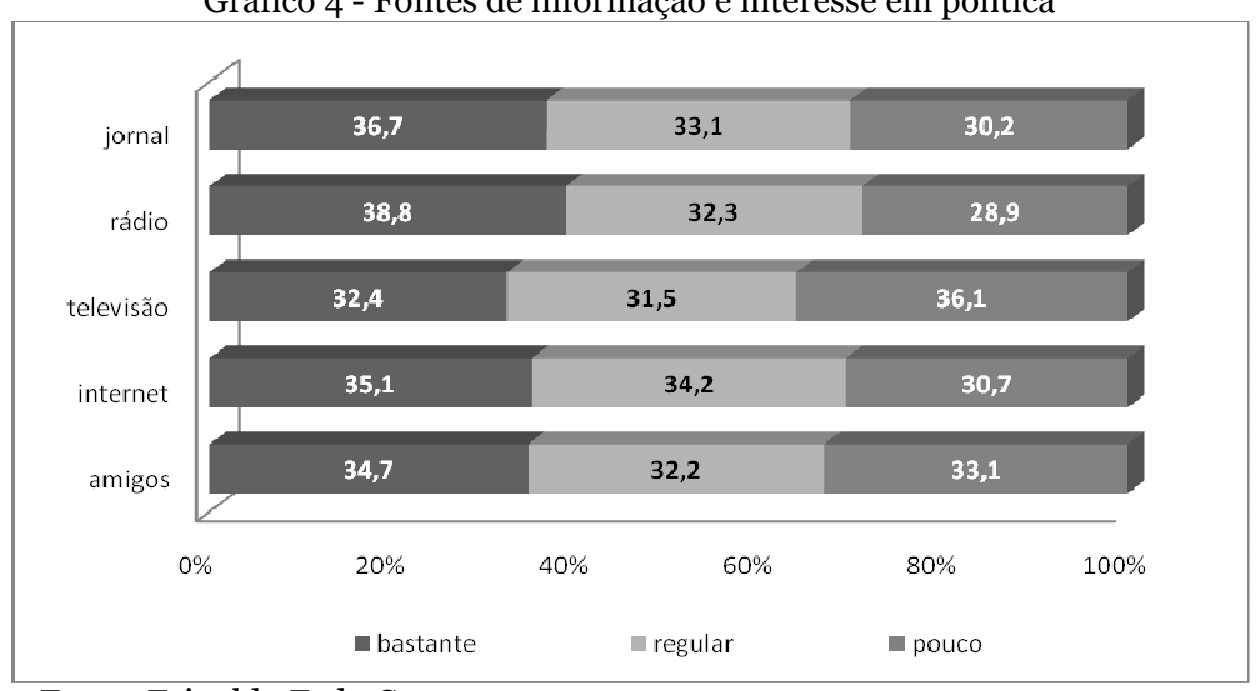

Fonte: Erinaldo F. do Carmo

Como existe uma relação forte entre as variáveis "idade" e "escolaridade", verificamos que a frequência de eleitores de menor escolaridade está associada aos eleitores mais velhos. Neste sentido, observa-se que há uma evidente particularidade neste grupo, que utiliza primordialmente a televisão na obtenção de informações: ele é composto por eleitores idosos, pouco familiarizados com a internet, e por eleitores de baixa escolaridade, pouco familiarizado com a leitura. Neste grupo, portanto, o jornal e o computador têm uma utilização reduzida.

O jornal é pouco utilizado, ainda, pelos eleitores mais jovens (entre 16 e 24 anos de idade), mas estes compensam a ausência deste meio com a utilização da internet. Estes dois veículos apresentam uma relação muito forte com o nível de instrução do eleitor: à medida que aumenta a escolaridade, aumenta também a utilização da internet e do jornal.

A utilização da internet como fonte de informação política ainda tem um uso reduzido em relação aos outros meios.7 Ela aparece como o instrumento menos utilizado pelos eleitores, porém é o que apresenta o maior crescimento, considerando os últimos pleitos.

$7 \mathrm{O}$ acesso à internet é limitado a 25\% dos eleitores brasileiros, na maioria integrantes das classes $\mathrm{A}$ e $\mathrm{B}$ (IBOPE/NetRating). 


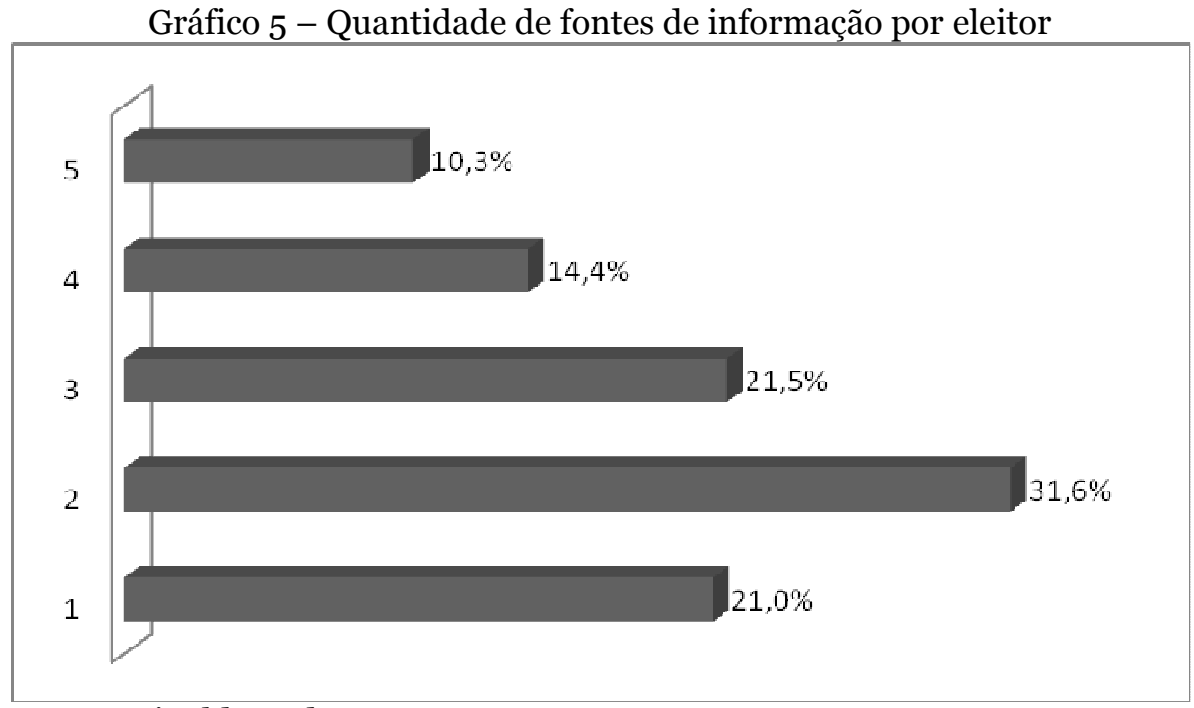

Fonte: Erinaldo F. do Carmo

Em todas as fontes de informação política utilizadas pelo eleitor, exceto a televisão, o uso é sempre maior entre os que possuem maior interesse em política. Quanto mais interesse o eleitor tem pela política, maior a utilização e a diversificação das fontes de informação. O gráfico 5 demonstra que a maior parte dos pesquisados faz uso de mais de uma fonte de informação política. 31,6\% usam duas fontes de informação, prioritariamente a televisão, além de um outro meio. 46,2\% usam três ou mais fontes, mas predominantemente a televisão. Entretanto, chama a atenção, de forma preocupante, o percentual de eleitores que utilizam apenas uma fonte de informação (21\%). Neste grupo de eleitores a única fonte de informação sobre questões políticas é, basicamente, a televisão. ${ }^{8}$

\section{CONSIDERAÇÕES FINAIS}

Uma primeira constatação deste trabalho, obtida a partir da observação dos pesquisados nos grupos focais, é que muitas das opiniões emitidas pelos eleitores sobre os candidatos e o processo eleitoral são provenientes da mídia e principalmente da televisão, com especial destaque para o Horário Eleitoral. Nos surveys, semelhantemente, notamos que a televisão se destaca entre os veículos midiáticos como fonte de informação política e o Horário Eleitoral como instrumento eficaz de comunicação entre candidatos e eleitores no período eleitoral.

Constatamos, ainda, que o Horário Eleitoral não se limita ao espaço e ao tempo de transmissão na TV, mas se prolonga nas relações sociais. Apesar da televisão e do rádio serem os meios mais usados para a obtenção de informações políticas, 41,2\%

\footnotetext{
${ }^{8}$ Dos entrevistados que utilizam apenas um meio como fonte de informação política, 81\% informaram que este meio é a televisão, $11 \%$ que é o rádio, $3 \%$ que é o jornal, $2 \%$ que são os amigos e 1\% a internet.
} 
dos eleitores também tomam conhecimento dos acontecimentos políticos através dos amigos e 63,2\% conversam com outras pessoas sobre política. Na comunicação interpessoal a propaganda eleitoral ganha vida através dos diálogos por ela gerados.

Nos diálogos ocorridos no espaço micropúblico, o eleitor destrói e reconstrói os discursos gerados na propaganda eleitoral. Por isso o seu papel na recepção da informação não pode ser subestimado. Em vez de inerte, ele atua; em vez de alienado, ele interage.

\section{REFERÊNCIAS BIBLIOGRÁFICAS}

ALbUQUerQue, Afonso de; DIAS, Maria Ribeiro. Partidos Políticos em Campanha: notas para uma metodologia de análise da propaganda política na televisão. Caxambu: XVI ANPOCS, out. 2002. (Anais).

ALDÉ, Alessandra. A Construção da Política: cidadão comum, mídia e atitude política. Rio de Janeiro: Iuperj, 2001. (Tese).

ALMEIDA, Alberto Carlos. A Cabeça do Brasileiro. São Paulo: Record, 2007.

BRAGA, Maria do Socorro Sousa. O processo partidário-eleitoral brasileiro: padrões de competição política (1982-2002). São Paulo Humanitas/Fapesp, 2006,

CARMO, Erinaldo Ferreira do. O Espaço Micropúblico. Recife: Universitária UFPE, 2010.

CERVI, Emerson Urizzi. Comportamento eleitoral volátil e reeleição: as vitórias de Jaime Lerner no Paraná. In: Sociologia e Política, n. 19, nov. 2002.

LIMA, Venício. A Mídia nas Eleições de 2oo6. São Paulo: Perseu Abramo, 2007.

LOURENÇO, Luiz Claudio. Abrindo a Caixa-Preta: da indecisão à escolha - a eleição presidencial de 2002. Rio de Janeiro: Iuperj, 2007. (Tese).

MATOS, Heloiza (org.). Mídia, Eleições e Democracia. São Paulo: Scritta, 1994.

OLIVEIRA, Luiz Ademir de. A Disputa Política na Televisão: uma análise das discursivas dos candidatos Fernando Henrique Cardoso e Luiz Inácio Lula da Silva no Horário Gratuito de Propaganda Eleitoral. Rio de Janeiro: Iuperj, 1999. (Dissertação).

VEIGA, Luciana. Em busca das razões para o voto: o uso que o homem faz do horário eleitoral. Rio de Janeiro: Iuperj, 2001. (Tese).

Em busca das razões para o voto: o uso que o eleitor faz da propaganda política. In: Contracampo, v. 7, 2002. 